\title{
Is reduced female survival after mating a by-product of male-male competition in the dung fly Sepsis cynipsea? Y Teuschl11, DJ Hosken ${ }^{1,2}$ and WU Blanckenhorn*1
} Address: ${ }^{1}$ Zoologisches Museum, Universität Zürich, Winterthurerstrasse 190, CH-8057 Zürich, Switzerland and ${ }^{2}$ Centre for Ecology \&
Conservation, School of Biosciences, University of Exeter, Cornwall Campus, Tremough, Penryn, Cornwall, TR10 9EZ, UK

Email: Y Teuschl - yteuschl@yahoo.com; DJ Hosken - D.J.Hosken@ex.ac.uk; WU Blanckenhorn* - wolfman@zm.uzh.ch

* Corresponding author

Published: 17 October 2007

BMC Evolutionary Biology 2007, 7:194 doi:10.1 186/147|-2/48-7-194

This article is available from: http://www.biomedcentral.com//47/-2/48/7//94

(C) 2007 Teuschl et al; licensee BioMed Central Ltd.

This is an Open Access article distributed under the terms of the Creative Commons Attribution License (http://creativecommons.org/licenses/by/2.0), which permits unrestricted use, distribution, and reproduction in any medium, provided the original work is properly cited.
Received: 14 April 2007

Accepted: 17 October 2007

\begin{abstract}
Background: In a number of species males damage females during copulation, but the reasons for this remain unclear. It may be that males are trying to manipulate female mating behaviour or their life histories. Alternatively, damage may be a side-effect of male-male competition. In the black scavenger or dung fly Sepsis cynipsea (Diptera: Sepsidae) mating reduces female survival, apparently because males wound females during copulation. However, this damage does not seem to relate to attempted manipulation of female reproduction by males. Here we tested the hypothesis that harming females during mating is an incidental by-product of characters favoured during precopulatory male-male competition. We assessed whether males and their sons vary genetically in their ability to obtain matings and harm females, and whether more successful males were also more damaging. We did this by ranking males' mating success in paired competitions across several females whose longevity under starvation was subsequently measured.
\end{abstract}

Results: As previously reported, our results show mating is costly for female S. cynipsea. However, variance in female longevity was not explained by male identity, family, body size, number of previous copulations, or copulation duration. Nevertheless, there was a positive correlation between the harm fathers inflicted on their mates (affecting female longevity) and the harm sons inflicted on theirs. Additionally, family identity significantly influenced male copulation success.

Conclusion: Our results indicate a heritable component of some yet unspecified male trait(s) that influence harm and mating success. However, there was no relationship between copulation success of fathers or sons and the mean longevity of their mates. We therefore found no support for harm being a side effect of traits favoured in pre-copulatory male-male competition.

\section{Background}

Males and females frequently have different optima for many aspects of reproduction including parental investment and mating frequency [1-6]. Reproduction is therefore potentially loaded with conflict (reviewed in [7-11]), and while conflicts are proceeding, there will be selection for manipulative abilities that allow one or the other sex to achieve their respective optima [12-14]. There are a number of ways to be manipulative, and all involve some cost to the manipulated party as they are moved away from their reproductive optima $[13,15]$, a situation recently termed conflict load [13]. 
In addition to conflict load, manipulative traits can impose further costs, termed harm, and these can be partly distinguished from conflict load by the fact that harm frequently seems to negatively impact on the fitness of the manipulating and the manipulated sex [13]. It is largely this fact that makes harm so difficult to understand (but see [16]), but an increasing number of studies document it. Perhaps the clearest cases involve males damaging females during copulation. For example, in the beetle Callosobruchus maculatus the male intromittent organ physically damages females, reducing female life-span [17] (but see [18]), and the traumatic insemination that occurs in the bed bug Cimex lectularius can also decrease female longevity [19]. Similarly, seminal fluids have been shown to negatively impact on female lifespan in Drosophila melanogaster [20], with sex-peptide recently being implicated in this phenomenon $[21,22]$.

Two general hypotheses have been proposed to explain the evolution of harm [13]. The adaptive harm hypothesis suggests that harm occurs because males are directly trying to manipulate female behaviour. This could occur if harm reduces the likelihood that females mate again, or prolongs remating intervals, because if either occurs, males increase the likelihood that females use their sperm [23]. Furthermore, males may be trying to manipulate female oviposition rates [24]. In this case, harm causes females to increase their reproductive output in a manner analogous to terminal investment. Models suggest that both of these strategies could in principle work $[23,24]$, but experimental tests of these ideas found no evidence to support them [25-27]. An alternative to adaptive harm is that harm is a side-effect of traits favoured by male-male competition $[13,28]$, and there is some evidence for this in Drosophila, where genotypes most successful in sperm competition are more damaging to females [29]. Analogous results are found in the cockroach Nauphoeta cineria, where malemale competition selects for males that reduce female fitness [30,31].

The black scavenger or dung fly Sepsis cynipsea (Diptera: Sepsidae) has also been extensively studied in this context. Females of this species show very conspicuous resistance behaviour to mating [32-34]. As soon as females arrive at dung pats for egg laying, they are mounted and guarded by males, and copulation only occurs after females have laid their eggs. Females that are unwilling to mate shake vigorously and extensively from side to side, bending their abdomen downwards until males leave [32], and only about $40 \%$ of the pairs that form in the field eventually copulate $[32,33,35]$. Males seem unable to force copulations [[36-38]; cf. [39]]. Female reluctance to mate in this species is seen as a classic example of conflict over mating $[25,34,36,37,40,41]$ and has been interpreted to result from high mating costs for females
$[33,36,40]$. In support of this interpretation, it has been shown that mated females have more wing injuries and die sooner than unmated females, with mortality apparently elevated by injuries to the female reproductive tract caused by male genitalia during copulation [42]; but compare [43] for another sepsid species). However, males do not appear to be benefiting from this harm by manipulating female oviposition or mating, because although injuries seem to increase with copulation number [42], females do not lower their remating rate or increase reproductive investment with increasing harm [25]. Post-oviposition copulations, which are generally rare but typical for sepsid flies [32,44], make advantages of injuring females during mating even less plausible: from a male perspective, females have to survive until they lay their next clutch because only then will females use the damaging male's sperm, but harming females reduces the likelihood they will survive to this point. Nevertheless, while we have no evidence for adaptive male harm, the possibility remains that harm represents collateral damage.

In this study we test the idea that injuring females during mating is a by-product of traits augmenting male reproductive success in pre-copulatory competition with other males. For example, extremely vigorous males may be better at securing copulations, but may also be rougher during copulation, analogous to the situation found in $D$. melanogaster [29]. In a laboratory experiment we assessed whether males differ in their ability to harm their mates, and compared fathers with their sons to estimate the heritability of this trait. At the same time we investigated whether or not male (fathers' and their sons') mating success, when in competition with other males, is positively correlated to female damage. Since we evaluated these questions at the family mean level, we also assessed whether or not there is additive genetic variation for these attributes [45-47].

\section{Results \\ Influence of reproduction on female residual longevity}

Before investigating specific male effects, we first investigated the effects of factors other than male characters (son experiment only). Females that copulated died earlier than control females of similar age that were not allowed to copulate (ANCOVA with copulation and temperature treatment as factors and body size as covariate: $F_{1,725}=$ 9.24, $p=0.002$; Fig. $1 \mathrm{a}$; cf. [41]). Flies of the $25^{\circ} \mathrm{C}$ treatment died sooner $\left(F_{1,725}=5.01 ; p=0.024 ;\right.$ Fig. $\left.1 \mathrm{a}\right)$. Larger females survived starvation for longer $\left(F_{1,725}=11.57 ; p=\right.$ 0.001 ), but only at $12^{\circ} \mathrm{C}$ (temperature by body size interaction: $F_{1,725}=20.02 ; p<0.001 ;$ Fig. $\left.1 b\right)$.

To specifically investigate the influence of egg laying on survival (as opposed to copulation plus egg laying, which were not differentiated in the previous analysis), $25^{\circ} \mathrm{C}$ 

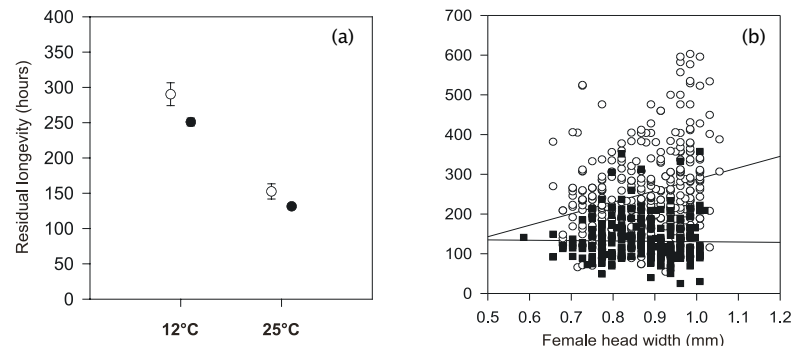

\section{Figure I}

Effects of (a) copulation (white circles no copulation; black circles one copulation) on (square-root-transformed) female residual longevity at $12^{\circ} \mathrm{C}$ and $25^{\circ} \mathrm{C}$ (in $\mathrm{h}$ ) and (b) body size on female residual longevity at $12^{\circ} \mathrm{C}$ (white circles) and $25^{\circ} \mathrm{C}$ (black circles) for copulated females only (son experiment).

flies were analyzed separately (because in the $12^{\circ} \mathrm{C}$ treatment females were not allowed to lay) in an ANCOVA with copulation as a factor and the number of clutches laid and female size as covariates. The number of clutches a female laid in the son experiment did not influence her residual longevity $\left(F_{1,310}=1.28 ; p=0.218\right)$. Similarly, egg number did not influence the residual longevity of the females mated with the fathers (Table 1).

\section{Influence of male identity on female residual longevity}

The residual longevity of females mated to the fathers was not influenced by male identity, the number of copulations a male previously had, female size or the total number of eggs females laid (Table 1). Residual longevity of females mated with sons was also tested, and here we included the fathers' identity as a random factor. Neither fathers' nor sons' identity had significant effects (Table 2).

To include male body size instead of male identity in an alternative analysis, the average female residual longevity of all his mating partners was calculated for each individual male (Tables 1 and 2 for fathers and sons, respectively). As in the analysis before, none of the variables, including male size, influenced residual longevity of females mated with the fathers (Table 1). Male size also did not influence the mean residual longevity of females mated with the sons (Table 2). There was a trend, apparently depending on male body size, for the residual longevity of females that mated with brothers to be similar (father identity effect and father identity by male size interaction in Table 2). As in the previous analyses, females mated with sons lived longer in the $12^{\circ} \mathrm{C}$ treatment and when they were larger (temperature effect and temperature by mean female size interaction in Table 2; $\mathrm{cf}$. above). Furthermore, females lived longer when they copulated for longer, but only at $12^{\circ} \mathrm{C}$ (temperature by mean copulation duration and temperature by mean copulation duration by female size interactions in Table 2). This is probably mediated by the fact that males copulate longer with larger females, and that large females live longer in the $12^{\circ} \mathrm{C}$ treatment (cf. above).

To investigate a possible heritability of harming females, mean residual longevity of all the mates of fathers and those of sons was compared in a parent-offspring regression including temperature treatment as a factor. There was a marginal overall relationship $\left(F_{1,55}=3.95 ; p=\right.$ 0.052 ; Fig. $2 \mathrm{a})$, caused by a strong and significant correlation in the $25^{\circ} \mathrm{C}$ treatment $\left(r=0.382\right.$; heritability $h^{2}=$ $0.73 \pm 0.35(\mathrm{SE}))$, while the association was weaker in the $12^{\circ} \mathrm{C}$ treatment $\left(r=0.199 ; h^{2}=0.60 \pm 0.58\right)$.

\section{Are some genotypes more successful in acquiring matings than others?}

In 200 of $370(54.9 \%)$ of the male pairs among fathers and 383 of $724(52.9 \%)$ of the male pairs among sons the red male was scored as winner, so the artificial colouring of the wings did not appear to influence a male's ability to secure copulations (binomial test for fathers: $p=0.132$; for sons: $p=0.128)$. As shown before [36], in direct competition in the laboratory the larger of two males is more likely to obtain copulations (binary logistic regression with the size difference between the interacting males as the dependent variable; for fathers: $p=0.017, n=230$; marginal effect for sons: $p=0.062, n=615$ ).

Table I: ANCOVA of the factors influencing individual (left) and family mean (right) (square-root-transformed) residual longevity of females mated with fathers (all non-significant interactions removed from the model)

\begin{tabular}{|c|c|c|c|c|c|c|c|c|c|}
\hline \multicolumn{5}{|l|}{ Residual longevity } & \multicolumn{5}{|l|}{ Mean residual longevity } \\
\hline & $d f$ & MS & $F$ & $P$ & & $d f$ & MS & $F$ & $P$ \\
\hline Egg number & 1 & 0.084 & 0.017 & 0.896 & Mean egg number & 1 & 1.182 & 1.072 & 0.306 \\
\hline Female size & I & 0.043 & 0.009 & 0.926 & Mean female size & I & 2.636 & 2.392 & 0.129 \\
\hline Copulation number & I & 4.758 & 0.965 & 0.327 & & & & & \\
\hline Male identity & 56 & 4.511 & 0.915 & 0.644 & Male size & I & 0.735 & 0.667 & 0.418 \\
\hline Error & 173 & 4.932 & & & Error & 46 & 1.102 & & \\
\hline
\end{tabular}


Table 2: ANCOVA of the factors influencing individual (left) and family mean (right) (square-root-transformed) residual longevity of females mated with sons (all non-significant interactions removed from the model)

\begin{tabular}{|c|c|c|c|c|c|c|c|c|c|}
\hline Residual longevity & $d f$ & MS & $F$ & $P$ & Mean residual longevity & $d f$ & MS & $F$ & $P$ \\
\hline Temperature & 1 & 722.107 & 106.549 & $<0.001$ & Temperature & 1 & 18.856 & 7.311 & 0.010 \\
\hline Son ID (father ID) & 21 & 7.762 & $\mathrm{I} .145$ & 0.307 & Male size & 1 & 0.000 & 0.000 & 0.989 \\
\hline Father ID & 17 & 6.044 & 0.782 & 0.695 & Father ID & 14 & 4.494 & 1.742 & 0.088 \\
\hline Female size & 1 & 15.007 & 2.214 & 0.139 & Mean female size & I & 1.173 & 0.455 & 0.504 \\
\hline $\begin{array}{l}\text { Copulation } \\
\text { duration }\end{array}$ & 1 & 3.685 & 0.544 & 0.462 & Mean copulation duration & 1 & 2.226 & 0.863 & 0.359 \\
\hline \multirow[t]{5}{*}{ Copulation number } & 1 & 0.027 & 0.004 & 0.949 & & & & & \\
\hline & & & & & Temperature $\times$ mean copulation duration & 1 & 17.693 & 6.860 & 0.013 \\
\hline & & & & & Temperature $\times$ mean female size & 1 & 17.406 & 6.749 & 0.013 \\
\hline & & & & & Male size $\times$ father ID & 14 & 4.519 & 1.752 & 0.086 \\
\hline & & & & & $\begin{array}{l}\text { Temperature } \times \text { mean copulation duration } \\
\times \text { mean female size }\end{array}$ & 2 & 8.712 & 3.378 & 0.045 \\
\hline Error & 162 & 6.777 & & & Error & 37 & 2.579 & & \\
\hline
\end{tabular}

To determine if male copulation success was similar for half brothers, the cumulative copulation success of each son (= proportion of encounters won against all competitors) was analyzed using ANCOVA with the father's identity as a random factor and the son's size as a covariate. The father's identity (i.e. family; $F_{46,125}=1.58, p=0.036$ ) significantly affected copulation success, suggesting a heritable component. However, at the same time cumulative copulation success of fathers and that of their sons was not significantly positively correlated $(r=0.132, n=47$, $p$ $=0.377$; Fig. 2b). Moreover, body size in this experiment also showed no heritable component in either a half-sib ANOVA design with father as random factor $\left(F_{49,147}=\right.$ $1.06 ; p=0.399)$ or a father-son correlation $(r=-0.058, n$ $=40, p=0.721$ ).
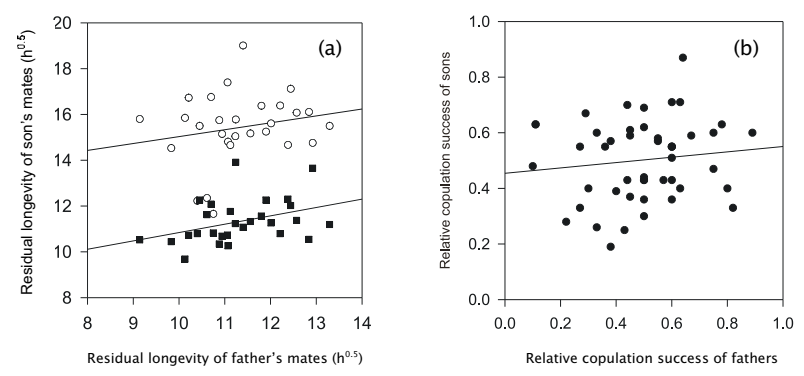

\section{Figure 2}

Family-mean regressions of (a) (square-root-transformed) residual longevity (in $\mathrm{h}$ ) of fathers' mates on that of their sons' mates at $12^{\circ} \mathrm{C}$ (white circles) and $25^{\circ} \mathrm{C}$ (black squares), and of (b) the cumulative copulation success of fathers on the cumulative copulation success of their sons (at $25^{\circ} \mathrm{C}$ ).

\section{Do mates of more successful males have reduced residual longevity?}

For fathers there was no relationship between their cumulative copulation success and the mean (square-roottransformed) residual longevity of their mates $(r=0.062$, $n=43, p=0.694$; Fig. 3a), nor was there such a relationship for the sons in the $12^{\circ} \mathrm{C}(r=-0.118, n=112, p=$ $0.215)$ or the $25^{\circ} \mathrm{C}$ treatment $(r=0.073, n=104, p=$ 0.460; Fig. 3b). However, it may be that a male's ability to harm their mating partner diminishes with his number of mates as he becomes sperm depleted or otherwise weakened. To test this, we first checked whether female residual longevity changed (i.e. here specifically increased) with her rank order as a mate of a particular male (= random effect); there was no such relationship for either fathers or sons at any of the two temperatures $(r<0.1, p>0.3)$. Furthermore, analogous to the first analysis above (Fig. 3), we further regressed a male's cumulative copulation success
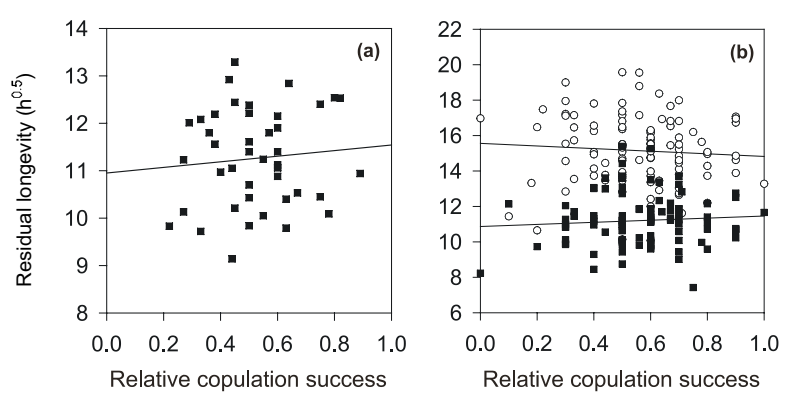

\section{Figure 3}

Regressions of the family (square-root-transformed) mean residual longevity (in $h$ ) of their mates on the cumulative copulation success of (a) fathers (at $25^{\circ} \mathrm{C}$ ) and (b) sons at $12^{\circ} \mathrm{C}$ (white circles) and $25^{\circ} \mathrm{C}$ (black squares). 
on the residual longevity of only his first mate, assuming his ability to harm females would be strongest and hence most apparent then. Again, there was no such relationship for either fathers or sons at any of the two temperatures $(r$ $<0.1, p>0.4)$.

\section{Discussion}

We did not find any support for the hypothesis that harming females is associated with success in pre-copulatory male-male competition in Sepsis cynipsea. We found some evidence for the heritability of both a male's ability to harm his mates (here measured as female residual longevity at two temperatures; Fig. 2a) and male mating success (here measured as the total number of copulations obtained). However, females that mated with more successful male genotypes did not have reduced residual longevity (Fig. 3), as would be expected if harm was a collateral effect of pre-copulatory male-male competition [29-31]. It is also unclear why the heritability of harm was quite high (Fig. 2a), but at the same time not repeatable across females of a given male. Nevertheless, in agreement with previous work, which found a negative association between copulation number and female longevity [42], mated females died sooner than unmated females, and this effect was largely independent of the number of clutches laid, i.e. female costs of reproduction. This contrasts markedly with results for a related sepsid fly (Saltella sphondylii), where copulation had no detectable effect on female longevity while egg laying did [48].

We also found (for sons) that females in the $25^{\circ} \mathrm{C}$ died sooner than those of the $12^{\circ} \mathrm{C}$ treatment (Fig. 1a). The main difference between these two treatments was that the former females lived for one week alone at $25^{\circ} \mathrm{C}$, where they could eat and oviposit, before they were moved to $12^{\circ} \mathrm{C}$. Their shorter residual longevity probably reflects a cost of reproduction and/or the added physiological demands of living at $25^{\circ} \mathrm{C}$. Interestingly, female size influenced residual longevity only in the $12^{\circ} \mathrm{C}$ treatment, where females were simply starved and could not reproduce, reflecting the relatively more efficient metabolism of larger individuals [49]. If females during their week in the $25^{\circ} \mathrm{C}$ treatment used most of their energy reserves to produce eggs, and if larger females utilize proportionally more energy for reproduction, this may explain the disappearance of the size relationship in the $25^{\circ} \mathrm{C}$ treatment. The relatively complex nature of these size-dependent effects on female residual longevity highlights the fact that we do not precisely know what makes mated females die more rapidly.

The $25^{\circ} \mathrm{C}$ treatment of the sons is directly comparable to that of the fathers, and indeed residual longevity of their mates was similar in absolute terms in both data sets (Fig. 2a), as would be expected if female mortality after mating is due at least in part to wounds inflicted by males [42]. However, female mortality was not influenced by male body size, male identity or copula duration. This differs from Drosophila melanogaster, where the preferred larger males harm and reduce female fitness more than smaller males [50,51]. In further contrast to D. melanogaster, where seminal fluid increases egg laying behaviour but shortens female lifespan [22,22], in S. cynipsea copulation does not appear to enhance egg laying [38] or be otherwise toxic for females, although in another study longer copulations did reduce the number of offspring a female produced [52]. Males in our experiment copulated multiply within a short time interval, which may influence the amount of ejaculate transferred to females. While we do not know how often males copulate in the field, or whether or not our males became ejaculate depleted here, the number of previous copulations a male had did not influence female residual longevity. Moreover, because particular males were not found to be generally more harmful, it does not seem that larger males are more damaging [cf. [42]].

Admittedly, in our experiment we might have missed the possibility that specific male genotypes are more harmful for specific female genotypes in a manner analogous to genetic incompatibility (e.g. $[53,54])$. For example, Nilsson and colleagues [55] showed that in the flour beetle Tribolium castaneum both female and male genotype influence female fitness in complex ways, with similar fitness interactions found in a range of taxa [56-58]. We cannot exclude such male-female interactions in S. cynipsea, as females copulating with the same male differed in their residual longevity. However, we cannot distinguish if this is merely random, purely female mediated or due to a female-male genotype interaction, because we did not vary female genotype (i.e. family) in the same manner as and independently from male genotype. Nevertheless, if levels of harm depend upon male-female interactions, the heritability of harm should be low, but it was not.

Our statistical support for the heritability of male harmfulness was not very strong overall, but our estimate is relatively high [cf. [59-62]]. Hoffmann [63] showed that heritability estimates for mating behaviour may be underestimated if they are based on single events; they can be much higher when several mating events are taken into account. This should not be a major problem here, as in our experiment heritability was estimated from at least four matings for each male and treatment, although the accuracy of estimates can still increase with the inclusion of up to six matings [63].

As previously shown in S. cynipsea, large males have a mating advantage in direct male-male competition [35,36]. However, in the current study this effect was only weak for 
sons. Our experimental design included several copulations within a short time, and large and otherwise superior males may have been exhausted and less successful in securing subsequent copulations. We have no data on the number of matings obtained by males in the field, although in nature males probably encounter more competitors, acquire fewer matings and are more stressed by additional environmental factors such as predators. In $S$. cynipsea the large male advantage is not primarily due to direct aggression between males. When both males were seen on top of the female and females were willing to copulate, the first male usually ended up as the winner; takeovers were recorded very infrequently. This suggests the winning males were generally the first ones to encounter and mount the female, which is comparable to previous results [36]. It is not clear if larger males are more active, faster, or if they constrain the activity of the smaller males in some way. However, virgin females tend to copulate with the first male encountered or not at all [38], and if larger males see, approach and mount females more readily, this would explain at least partly the large male advantage found in the field and the laboratory $[33,35,36,64$, 65].

Body size in S. cynipsea is heritable $[62,66]$, but highly phenotypically plastic, depending on temperature and the amount of larval food (dung) available [67]. Our failure to detect significant size heritability in this study may be because we did not control larval food levels. However, this was done on purpose as it allowed us to disentangle purely size-mediated effects and the genetic quality of males independent of size. On the other hand, larval food availability can influence adult condition and may therefore mask underlying genotypic effects to some degree. Despite this potential confound, we found significant family influences on mating success, although the nonsignificant father-son body size correlation suggests that some genetic male quality other than size underlies this.

\section{Conclusion}

Overall, our study provided no evidence that harming females during copulation is a by-product of some other trait increasing a male's success in pre-copulatory malemale competition; at least there is no simple linear effect. Since previous studies also failed to identify advantages to males harming females $[25,42]$, the reasons for male harm remain enigmatic in S. cynipsea. However, we only investigated pre-copulatory male-male competition. Harming females may correlate with some post-copulatory advantages such as sperm competitive ability [28-30]. To date we have little information on post-copulatory sexual selection in S. cynipsea (but see [68]), but if post-copulatory male-male competition were associated with harm levels, harmfulness could still be heritable, and we found some evidence for this. Alternatively, the greater mortality of mated females may be an inescapable cost of mating per se or of some associated physiological processes, independent of any male-female reproductive conflict. It would be helpful if we could identify the exact mechanism increasing female mortality after mating in this species. To date our data suggest that harm persists not because of associations between harming females and advantages in male-male or male-female interactions, but because it is a pleiotropic (i.e. non-adaptive) effect of mating itself. One other possibility is that harm persists because interactions between male-female genotypes generate variability in the damage inflicted, rendering selection against single male genotypes ineffective. All of these questions will be the subject of future investigations.

\section{Methods}

Flies used in this experiment stemmed from a laboratory population kept at standard conditions with sugar, pollen, water and dung at $25^{\circ} \mathrm{C}, 60 \%$ relative humidity and $12 \mathrm{~h}$ photoperiod. The population was initially started with 120 flies collected on two days in May 2002 in Fehraltorf, near Zürich, Switzerland. To generate virgins for experiments, individuals were sexed upon emergence and housed in single-sex group containers.

To test whether or not some males inflict more damage to females than others and if male harm is heritable, we compared the survival of females that copulated with the same males, and we compared their survival to the survival of females that copulated with the sons of these males. Additionally we compared the copulation success of fathers and sons.

\section{Treatment of fathers}

To distinguish competing males, the wings of 60 males were coloured randomly either with red or green colour, so that half of the males were red and the other half were green. In each trial, up to 15 random pairs of males were transferred into a $50 \mathrm{ml}$ test vial (2 males/vial). To each of these pairs a virgin female aged of $3-5$ days (when they are most receptive: [38]) was added and the three flies were observed. If females shook vigorously for approximately $10 \mathrm{~min}$ they were exchanged for other females. Longer persistence of males does not significantly increase their probability of copulating [36], and $80 \%$ of all copulations occur within the first 10 min after the first male mating attempt. Furthermore, shaking indicates female unwillingness to mate, more so than assessment of male quality [36]. Indeed, if the females were shaking vigorously for some time, they usually did so with both males. Females were exchanged up to 5 times until one of the two males obtained a copulation; if by then no copulations had occurred, the pair was not scored. The copulating male was scored as the winner of a pair. After all pairs were scored, males were rotated to obtain new (random) com- 
binations of red-green male pairs, and the process was repeated using different females until each male was tested in 10 different trials against 10 different males. These trials were spread over 2-4 days. Only males with more than six completed trials were included in the final analysis.

\section{Treatment of mothers}

After copulation females were held alone in $100 \mathrm{ml}$ vials with sugar, pollen and water and kept at $25^{\circ} \mathrm{C}$ and $60 \%$ relative humidity for 10 days. A maximum of 5 females that copulated with a given male were kept. To obtain 5 mates for each male, those males that did not achieve 5 copulations were given the possibility to copulate with females without a competitor. Females were provided thrice with fresh cow dung for egg laying over 1 week. To generate offspring for the son experiment, eggs were counted and each dung portion with eggs was transferred into plastic containers and kept at $25^{\circ} \mathrm{C}$ (offspring are not produced or take forever to emerge at $12^{\circ} \mathrm{C}$ ). Offspring were counted at emergence and sons were held separated by family to test them in a manner similar to their fathers (as described below).

To estimate the magnitude of harm to females, after their third egg laying opportunity females were transferred into $50 \mathrm{ml}$ glass vials containing only water, and moved to a $12^{\circ} \mathrm{C}$ climate chamber, where they were checked three times per day for death. At colder temperatures physiological processes slow down and females survive longer, producing greater variation in longevity. This treatment served to enhance the likelihood of detecting mortality differences inflicted by individual males, especially because stress is frequently required for experimental effects to become manifest $[69,70]$, as shown previously for this species [41]. In what follows, the survivorship in the $12^{\circ} \mathrm{C}$ climate chamber under complete starvation is referred to as residual longevity, but this measure is equivalent to the term starvation resistance used in the Drosophila literature [71].

\section{Treatment of sons}

Three sons from different mothers (i.e. half brothers) were tested in exactly the same way as their fathers (described above). All mates of these males were kept and split randomly into two groups: a $12^{\circ} \mathrm{C}$ and a $25^{\circ} \mathrm{C}$ treatment. $12^{\circ} \mathrm{C}$ females were transferred immediately after copulation into vials containing water and moved into a $12^{\circ} \mathrm{C}$ climate chamber; $25^{\circ} \mathrm{C}$ females were given the possibility to lay eggs thrice, during which time they were kept at $25^{\circ} \mathrm{C}$ with sugar, pollen and water. Eggs were not counted; we only checked whether or not a female laid. After 1 week these females were also moved to the $12^{\circ} \mathrm{C}$ climate chamber with only water. We did this because the mating wounds females incur during copulation may only have a negative effect after egg laying into cow dung. Additionally, this treatment was directly comparable to the one used for the fathers' mates described above. Again, we checked three times per day for death. As a control, 2 $\times 50$ unmated females of approximately the same age were chosen randomly from the female group container and subjected to the $12{ }^{\circ} \mathrm{C}$ and $25^{\circ} \mathrm{C}$ treatments.

\section{Statistical analyses}

Head width of all males, their mates and the control females was measured under a dissecting microscope at $40 \times$ magnification and included in all analyses as a covariate. Head width is a good estimate of body size in this species [66].

Residual longevity (after copulation) was square-root transformed and outliers were excluded (i.e. data points more than 3 standard errors away from the mean), as they may indicate inadvertent access to nutrients. Only copulation durations longer than $10 \mathrm{~min}$ and shorter than 60 minutes were included. In statistical analyses including male identity, only males that copulated with at least three females were included. In the analysis of the sons only males mated to at least two females in each temperature treatment were included. In analyses including fathers and sons only fathers with data for more than two sons were included.

\section{Competing interests}

The author(s) declares that there are no competing interests.

\section{Authors' contributions}

All three authors contributed to the design of the study and participated equally in the execution of the experiments. YT wrote the initial manuscript as part of her Ph.D. thesis, and DJH and WUB contributed substantially in writing and re-writing. YT performed the statistical analyses with assistance from WUB. All authors have read and approved the final version of this manuscript.

\section{Acknowledgements}

We thank the Swiss National Fund for financing this project. DJH also thanks the European Social Fund and NERC for support. Thanks also to T. Morrow, M. Edvardsson, T. Tregenza, N. Wedell, M. Taylor, O. Martin and F. Champion de Crespigny for kindly commenting on previous versions of this manuscript.

\section{References}

I. Bateman AJ: Intra-sexual selection in Drosophila Heredity. 1948, 2:349-368.

2. Trivers RL: Parental investment and sexual selection. In Sexual Selection and the Descent of Man Edited by: Campbell B. Chicago IL, Aldine Press; 1972:136-179.

3. Parker GA: Sexual selection and sexual conflict. In Sexual selection and reproductive competition in insects Edited by: Blum MS, Blum NA. London, Academic Press; 1979:123-166.

4. Thornhill R, Alcock J: The Evolution of Insect Mating Systems Cambridge MA, Harvard University Press; 1983. 
5. Partridge L, Hurst LD: Sex and conflict. Science 1998, 28 I:2003-2008.

6. Lessels CM: Sexual conflict in animals. In Levels of Selection Edited by: Keller L. Princeton NJ, Princeton University Press; 1999:75-99.

7. Chapman T, Arnqvist G, Bangham J, Rowe L: Sexual conflict. Trends Ecol Evol 2003, I 8:4 I-47.

8. Arnqvist G, Rowe L: Sexual Conflict Princeton NJ, Princeton University Press; 2005.

9. Hosken D, Snook R: How important is sexual conflict? Am Nat 2005, I65:SI-S4

10. Tregenza T, Wedell N, Chapman T: Introduction. Sexual conflict: A new paradigm? Phil Trans R Soc Lond B 2006, 3 I 6:229-234.

II. Wedell N, Kvarnemo C, Lessells CM, Tregenza T: Sexual conflict and life histories. Anim Behav 2006, 71:999-1011.

12. Holland B, Rice WR: Chase-away sexual selection: antagonistic seduction versus resistance. Evolution 1998, 52:I-7.

13. Lessells CM: The evolutionary outcome of sexual conflict. Phil Trans Roy Soc Lond B 2006, 36 I:301-317.

14. Parker GA: Sexual conflict over mating and fertilization: an overview. Phil Trans Roy Soc Lond B 2006, 36 I:235-259.

15. Rice WR: Intergenomic conflict interlocus antagonistic coevolution and the evolution of reproductive isolation. In Endless Forms: Species and Speciation Edited by: Howard DJ, Berlocher SH. Oxford, Oxford University Press; 1998:261-270.

16. Eberhard WG: Evolutionary conflicts of interest: are female sexual decisions different? Am Nat 2005, 165:S19-S25.

17. Crudgington HS, Siva-Jothy MT: Genital damage kicking and early death. Nature 2000, 407:855-856

18. Eady PE, Hamilton L, Lyons RE: Copulation, genital damage and early death in Callosobruchus maculatus. Procs Roy Soc Lond $B$ 2007, 274:247-252

19. Stutt $A D$, Siva-Jothy $M T$ : Traumatic insemination and sexual conflict in the bed bug Cimex lectualarius. Proc Natl Acad Sci USA 200I, 98:5683-5687.

20. Chapman T, Lidde LF, Kalb JM, Walfran MF, Partridge L: Cost of mating in Drosophila melanogaster females is mediated by male accessory gland products. Nature 1995, 373:24I-244.

21. Gems D, Riddle DL: Longevity in Caenorhabditis elegans reduced by mating but not gamete production. Nature 1996 , 379:723-725.

22. Wigby $\mathrm{S}$, Chapman $\mathrm{T}$ : Sex peptide causes mating costs in female Drosophila melanogaster. Curr Biol 2005, I 5:3 | 6-32 I.

23. Johnstone RA, Keller L: How males can gain by harming their mate: sexual conflict seminal toxins and the cost of mating. Am Nat 2000, I 56:368-377.

24. Lessells CM: Why are males bad for females? Models for the evolution of damaging male mating behaviour. Am Nat 2005 165:S46-S63.

25. Hosken DJ, Martin OY, Born J, Huber F: Sexual conflict in Sepsis cynipsea : female reluctance fertility and mate choice. J evol Biol 2003, 16:485-490.

26. Morrow EH, Arnqvist G, Pitnick S: Adaptation versus pleiotropy: why do males harm their mates? Behav Ecol 2003, 14:802-806.

27. Edvarsson M, Tregenza $T$ : Why do Callosobruchus maculates harm their mates? Behav Ecol 2005, 16:788-793.

28. Stockley P: Sexual conflict resulting from adaptations to sperm competition. Trends Ecol Evol 1997, 12:154-159.

29. Civetta A, Clark AG: Correlated effects of sperm competition and postmating female mortality. Proc Natl Acad Sci USA 2000 97:13162-13165.

30. Moore AJ, Gowaty PA, Moore PJ: Females avoid manipulative males and live longer. J evol Biol 2003, 16:523-530.

31. Moore AJ, Moore PJ: Balancing sexual selection through opposing mate choice and mate competition. Proc Roy Soc Lond $B$ 1999, 266:7||-716.

32. Parker GA: Reproductive behaviour of Sepsis cynipsea (L) (Diptera - Sepsidae). I. A preliminary analysis of the reproductive strategy and its associated behaviour patterns. Behaviour 1972, 41:172-206.

33. Ward PI, Hemmi J, Röösli T: Sexual conflict in the dungfly Sepsis cynipsea. Funct Ecol 1992, 6:649-653.

34. Allen GR, Simmons LW: Coercive mating fluctuating asymmetry and male mating success in the dung fly Sepsis cynipsea. Anim Behav 1996, 52:737-741.

35. Ward PI: The effects of size on the mating behaviour of the dung fly Sepsis cynipsea. Behav Ecol Sociobiol 1983, 13:75-80.
36. Blanckenhorn WU, Mühlhäuser $C$, Morf $C$, Reusch T, Reuter M: Female choice female reluctance to mate and sexual selection on body size in the dungfly Sepsis cynipsea. Ethology 2000 , 106:577-593.

37. Ding A, Blanckenhorn WU: The effect of sexual size dimorphism on mating behaviour in two dung flies with contrasting dimorphism. Evol Ecol Res 2002, 4:259-273.

38. Teuschl Y, Blanckenhorn WU: The reluctant fly: What makes Sepsis cynipsea females willing to copulate? Anim Behav 2007, 73:85-97.

39. Eberhard WG: The function of female resistance behavior: Intromissiom by male coercion vs female cooperation in Sepsis flies (Diptera: Sepsidae). Rev Biol Trop 2002, 50:485-505.

40. Mühlhäuser $C$, Blankenhorn WU: The costs of avoiding matings in the dung fly Sepsis cynipsea. Behav Ecol 2002, 13:359-365.

4I. Martin OY, Hosken DJ: Costs and benefits of evolving under experimentally enforced polyandry or monogamy. Evolution 2003, 57:2765-2772.

42. Blanckenhorn WU, Hosken DJ, Martin OY, Reim C, Teuschl Y, Ward PI: The costs of copulating in the dung fly Sepsis cynipsea. BehavEcol 2002, 13:353-358.

43. Eberhard WG, Huber BA: Copulation and sperm transfer in Archisepsis flies (Diptera: Sepsidae) and the evolution of their intromittent genitalia. Stud Dipterol 1998, 5:217-248.

44. Schulz KS: The Evolution of Mating Systems in Black Scavenger Flies (Diptera: Sepsidae) PhD Dissertation University of Arizona; 1999.

45. Roff DA: The estimation of genetic correlations from phenotypic correlations: a test of Cheverud's conjecture. Heredity 1995, 74:48|-490.

46. Roff DA: Evolutionary Quantitative Genetics New York, Chapman \& Hall; 1997.

47. Astles PA, Moore AJ, Preziosi RF: A comparison of methods to estimate cross-environment genetic correlations. J evol Biol 2006, 19:1|4-122

48. Martin OY, Hosken DJ: Copulation reduces male but not female longevity in Saltella sphondylii (Diptera: Sepsidae). evol Biol 2004, 17:357-362.

49. Reim C, Teuschl Y, Blanckenhorn WU: Size-dependent effects of temperature and food stress on energy stores and survival in yellow dung flies (Diptera: Scathophagidae). Evol Ecol Res 2006, 8:1215-1234

50. Pitnick S, Garcia-Gonzalez F: Harm to females increases with male body size in Drosophila melanogaster. Proc $R$ Soc Lond $B$ 2002, 269: $1821-1828$.

5I. Friberg $U$, Arnqvist G: Fitness effects of female mate choice: preferred males are detrimental for Drosophila melanogaster females. J evol Biol 2003, 16:797-8I I.

52. Martin OY, Leugger RR, Zeltner N, Hosken DJ: Male age mating probability and mating costs in the fly Sepsis cynipsea. Evol Ecol Res 2003, 5: 119-129.

53. Zeh JA, Zeh DW: The evolution of polyandry: intragenomic conflict and genetic incompatibility. Proc $R$ Soc Lond $B$ 1996, 263:17|I-1717

54. Tregenza T, Wedell N: Genetic incompatability mate choice and patterns of parentage. Mol Ecol 2000, 9:1013-1027.

55. Nilsson T, Fricke $C$, Arnqvist G: Patterns of divergence in the effects of mating on female reproductive performance in flour beetles. Evolution 2002, 56:III-I 20.

56. Clark AG, Begun DJ, Prout T: Female $\times$ male interactions in Drosophila sperm competition. Science 1999, 283:217-220.

57. Miller GT, Pitnick S: Sperm-female coevolution in Drosophila. Science 2002, 298: 1230-1233.

58. Hosken DJ, Blanckenhorn WU, Garner TWJ: Heteropopulation males have a fertilization advantage during sperm competition in the yellow dung fly (Scathophaga stercoraria). Proc $R$ Soc Lond B 2002, 269:170I-1707.

59. Mousseau TA, Roff DA: Natural selection and the heritability of fitness components. Heredity 1987, 59:181-197.

60. Roff DA, Mousseau TA: Quantitative genetics and fitness: lessons from Drosophila. Heredity 1987, 58: 103-I I8.

6I. Price T, Schluter D: On the heritability of life-history traits. Evolution I991, 45:853-861.

62. Mühlhäuser C, Blanckenhorn WU: The quantitative genetics of sexual selection in the dung fly Sepsis cynipsea. Behaviour 2004, | 41:327-341. 
63. Hoffmann AA: Is the heritability for courtship and mating speed in Drosophila (fruit fly) low? Heredity 1999, 82: I58-162.

64. Kraushaar U, Blanckenhorn WU: Population variation in sexual selection and its effect on size allometry in two dung fly species with contrasting sexual size dimorphism. Evolution 2002, 56:307-321.

65. Blanckenhorn WU, Kraushaar U, Teuschl Y, Reim C: Sexual selection on morphological and physiological traits and fluctuating asymmetry in the black scavenger fly Sepsis cynipsea. J evol Biol 2004, 17:629-64I.

66. Reusch T, Blanckenhorn WU: Quantitative genetics of the dung fly Sepsis cynipsea : Cheverud's conjecture revisited. Heredity 1998, 8I:III-II9.

67. Blanckenhorn WU: Different growth responses to temperature and resource limitation in three fly species with similar life histories. Evol Ecol 1999, 13:395-409.

68. Martin OY, Hosken DJ: Strategic ejaculation in the common dung fly Sepsis cynipsea. Anim Behav 2002, 63:54I-546.

69. Hoffmann AA, Parsons PA: Evolutionary Genetics and Environmental Stress Oxford, Oxford University Press; 1991.

70. Wilkinson GS: Reciprocal food sharing in the vampire bat. Nature 1984, 308: I8I-I84.

7I. Harshman LG, Hoffmann AA, Clark AG: Selection for starvation resistance in Drosophila melanogaster : physiological correlates enzyme activities and multiple stress responses. J evol Biol 1999, I 2:370-379.

Publish with Bio Med Central and every scientist can read your work free of charge

"BioMed Central will be the most significant development for disseminating the results of biomedical research in our lifetime. "

Sir Paul Nurse, Cancer Research UK

Your research papers will be:

- available free of charge to the entire biomedical community

- peer reviewed and published immediately upon acceptance

- cited in PubMed and archived on PubMed Central

- yours - you keep the copyright

Submit your manuscript here:

http://www.biomedcentral.com/info/publishing_adv.asp 